\title{
OTIMIZAÇÃO ENERGÉTICA DE COLUNAS DE DESTILAÇÃO ATMOSFÉRICA E A VÁCUO PARA PETRÓLEO EM FUNÇÃO DO ${ }^{\circ} A P I$ DA CARGA
}

\author{
C. B. Sousa, V. A. M. Gomes, S. M. P. Lucena \\ Universidade Federal do Ceará, Departamento de Engenharia Química \\ E-mail para contato: caiobragasousa@gmail.com
}

\begin{abstract}
RESUMO - Duas colunas de destilação de petróleo em série, uma atmosférica e outra a vácuo, foram simuladas com o uso do software Aspen HYSYS 7.3. Foram utilizados dados experimentais de ${ }^{\circ}$ API e de PEV (Ponto de Ebulição Verdadeiro) de 30 correntes de petróleo diferentes. O pacote termodinâmico utilizado em todas as simulações foi a equação de Peng-Robinson. Uma otimização energética foi realizada com a construção de uma simulação para cada petróleo selecionado, mantendo os mesmos níveis de produção das retiradas laterais. As simulações demonstraram que a depender do decréscimo do parâmetro ${ }^{\circ} \mathrm{API}$, não é energeticamente viável manter duas colunas de destilação operando em série, mas somente uma coluna operando a vácuo, no intuito de manter os mesmos níveis de produção. De um modo inverso, com o aumento deste parâmetro, é mais viável o processo com as duas colunas em série. Portanto, um intervalo de valores de ${ }^{\circ} \mathrm{API}$ foi obtida como viragem, sendo este um critério para projetos futuros.
\end{abstract}

\section{INTRODUÇÃO}

No contexto do refino de petróleo, as operações de destilação atmosférica e a vácuo constituem as suas operações unitárias mais importantes. Seus produtos, também chamados de cortes (cuts), são matérias primas (feedstocks) para os diversos processos subsequentes (ou processos de downstream). Portanto, com poucas exceções, essas unidades trabalhando em conjunto constituem o "coração" de quase todas as refinarias (Gary; Handwerk, 2001).

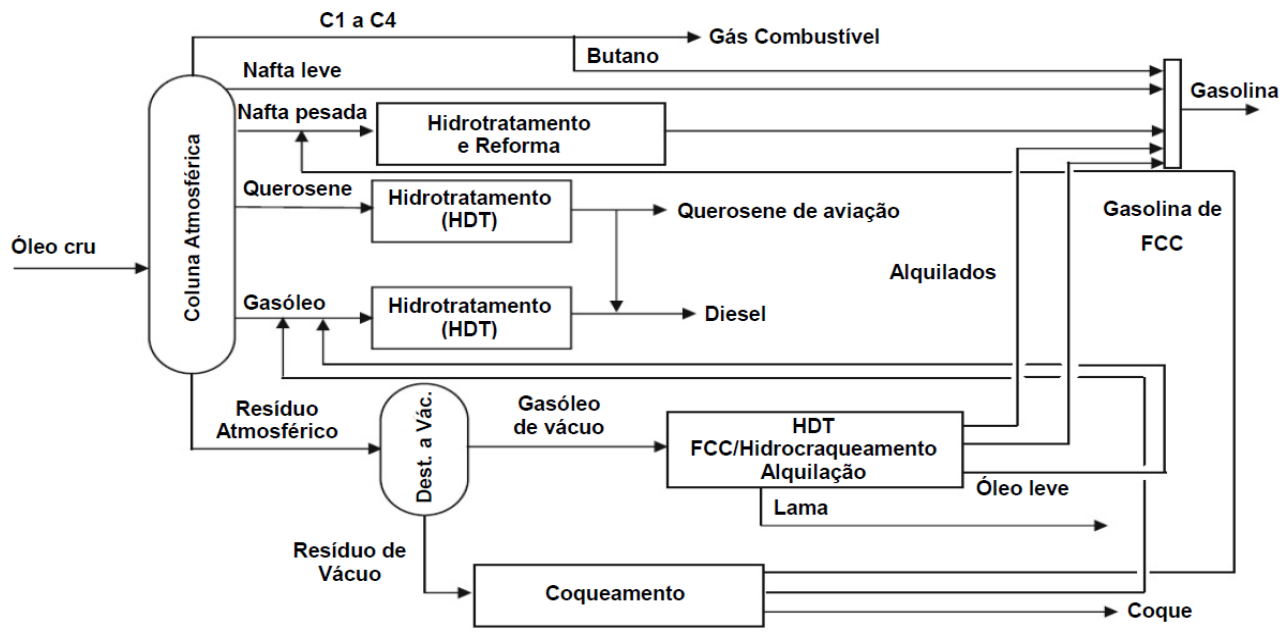

Figura 1 - Diagrama de blocos para uma refinaria típica. 
A Figura 1, adaptada de Fahim et al. (2009), mostra um Diagrama de Blocos de uma refinaria típica, onde as unidades de destilação atmosférica e a vácuo ocupam uma posição de fundamental importância no processo completo.

Essas operações unitárias juntas são consideradas as mais energo-intensivas. Em geral, somente a destilação atmosférica demanda cerca de $40 \%$ de toda a energia consumida numa refinaria (Szklo; Uller, 2008). Sendo assim, é frequente o uso das correntes quentes recémsaídas da coluna para aquecer a carga de petróleo cru. Este processo é feito pelo uso dos chamados pré-aquecedores de carga: trocadores de calor do tipo casco e tubos. A temperatura típica necessária para a entrada da carga de petróleo numa coluna atmosférica está situada em torno de 330 a $385^{\circ} \mathrm{C}$. Com a introdução dos pré-aquecedores, a temperatura da carga pode ser elevada para valores de $120^{\circ} \mathrm{C}$ a $150^{\circ} \mathrm{C}$ antes de entrar na fornalha. Este aumento de temperatura nos pré-aquecedores representa uma grande economia de energia para o processo global (Fahim et al., 2009). No entanto, mesmo com essa integração energética de processo, essas operações unitárias ainda consomem grandes quantidades de energia, sendo que diversos trabalhos foram publicados na literatura sobre otimização energética em função de alguns parâmetros.

Um ponto importante que diferencia as unidades atmosférica e a vácuo das refinarias em relação a outras unidades de destilação refere-se ao não uso de um refervedor. Ao invés disso é injetado vapor d'água superaquecido diretamente no fundo coluna. Este procedimento se justifica pelos seguintes motivos (Yamanishi, 2007):

- Os estágios da seção de esgotamento podem alcançar temperaturas muito elevadas. Com o refervedor, as temperaturas destes estágios podem ultrapassar a temperatura de formação de coque, que não deve ocorrer de forma alguma. Se isso ocorrer o refervedor estará comprometido, pois o coque formado se depositará na superfície dos tubos, reduzindo a eficiência de troca térmica;

- O refervedor teria um custo extremamente alto de instalação devido principalmente a grande área de troca térmica que seria necessária;

- A fração da alimentação vaporizada utilizando o refervedor é menor se comparada ao uso do vapor d'água.

Adicionalmente, a injeção direta de vapor no fundo da coluna desloca o equilíbrio termodinâmico de reações químicas de formação de coque no sentido dos reagentes, inibindo a formação deste (Bombardelli et al., 2005). No entanto, tal estratégia não evitará reações craqueamento no fundo das colunas se as temperaturas não estiverem abaixo de limites aceitáveis: em geral em torno de $450^{\circ} \mathrm{C}$. Tais temperaturas de fundo tendem a aumentar com aumento do ${ }^{\circ}$ API da carga (Fahim et al., 2009).

A hipótese inicial para este trabalho foi a de estudar o efeito do parâmetro ${ }^{\circ}$ API na carga térmica e nas temperaturas de fundo de duas colunas destilação. Para este estudo foram feitas simulações no software ASPEN HYSYS 7.3, onde correntes de petróleo com propriedades termodinâmicas conhecidas foram caracterizadas. O objetivo foi o de avaliar a necessidade de duas colunas operando em série, ou somente uma coluna vácuo, de tal modo a 
manter os mesmos níveis produção com menores gastos energéticos e com menores temperaturas de fundo possíveis, de tal forma a evitar possíveis reações de craqueamento térmico.

\section{FONTES DE DADOS EXPERIMENTAIS}

Foram utilizados dados experimentais de ${ }^{\circ}$ API e de PEV (Ponto de Ebulição Verdadeiro) de 30 correntes de petróleo diferentes.

Tabela 1 - Correntes de petróleo selecionadas

\begin{tabular}{|l|l|l|c|}
\hline Código & Fonte & País de Origem & ${ }^{\circ}$ API \\
\hline ZUATA & Bellet (1998) & Venezuela & 8,10 \\
\hline San Joaquim & AspenTech & EUA & 15,30 \\
\hline MEREY & Bellet (1998) & Venezuela & 16,00 \\
\hline Bozhong & Chevron & China & 16,90 \\
\hline Eocene & Chevron & Kuwait & 18,29 \\
\hline SYNBI SHB & TOTAL & Canadá & 19,02 \\
\hline Frade & Chevron & Brasil & 19,81 \\
\hline Chade Doba Blend & ExxonMobil & Chade & 21,40 \\
\hline KEARL & ExxonMobil & Canadá & 22,59 \\
\hline DOBA10X & ExxonMobil & Chade & 22,90 \\
\hline DALIA08X & ExxonMobil & Angola & 23,10 \\
\hline Ratawi & Chevron & Kuwait & 24,20 \\
\hline PAZFLOR & TOTAL & Angola & 25,30 \\
\hline HUNGO08Z & ExxonMobil & Angola & 28,30 \\
\hline VOLVE11X & ExxonMobil & Noruega & 28,80 \\
\hline GRSOL09X & ExxonMobil & Angola & 29,90 \\
\hline MONDO11 & ExxonMobil & Angola & 30,00 \\
\hline OMAN & ExxonMobil & Omã & 30,50 \\
\hline ANS11U & ExxonMobil & EUA & 31,40 \\
\hline HOOP212X & ExxonMobil & EUA & 32,20 \\
\hline THUND12Z & ExxonMobil & EUA & 32,90 \\
\hline MEDANITO & TOTAL & Argentina & 33,00 \\
\hline MASILA & TOTAL & Iémen & 34,09 \\
\hline EA BLEND & TOTAL & Nigéria & 35,03 \\
\hline BONNY LIGHT & TOTAL & Nigéria & 35,09 \\
\hline RABI LIGHT & TOTAL & Gabão & 35,80 \\
\hline QUAIB10U & ExxonMobil & Nigéria & 36,00 \\
\hline AZRLT11X & ExxonMobil & Azerbaijão & 36,10 \\
\hline UMM SHAIFF & Abu Dhabi & 36,93 \\
\hline GLFKB07X & Noruega & 37,80 \\
\hline
\end{tabular}


A Tabela 1 mostra as correntes que foram selecionadas com os seus respectivos valores de ${ }^{\circ}$ API. As correntes de cada petróleo foram identificadas por códigos padronizados que representam o campo de produção, e também por seus países de origem. Os dados utilizados estão disponibilizados gratuitamente em sua maioria nos sites oficiais das seguintes empresas petrolíferas: TOTAL S. A. ${ }^{\circledR}$, ExxonMobil ${ }^{\circledR}$ e Chevron ${ }^{\circledR}$. Dados experimentais de três petróleos também foram extraídos de Bellet (1998) e Aspen HYSYS (2004).

\section{DESENVOLVIMENTO DAS SIMULAÇÕES}

Um Diagrama de Fluxo de Processo foi tomado como padrão (PFD) para todas as unidades de destilação simuladas neste trabalho. A Figura 1 mostra o PFD padrão construído com os dados obtidos de simulação.

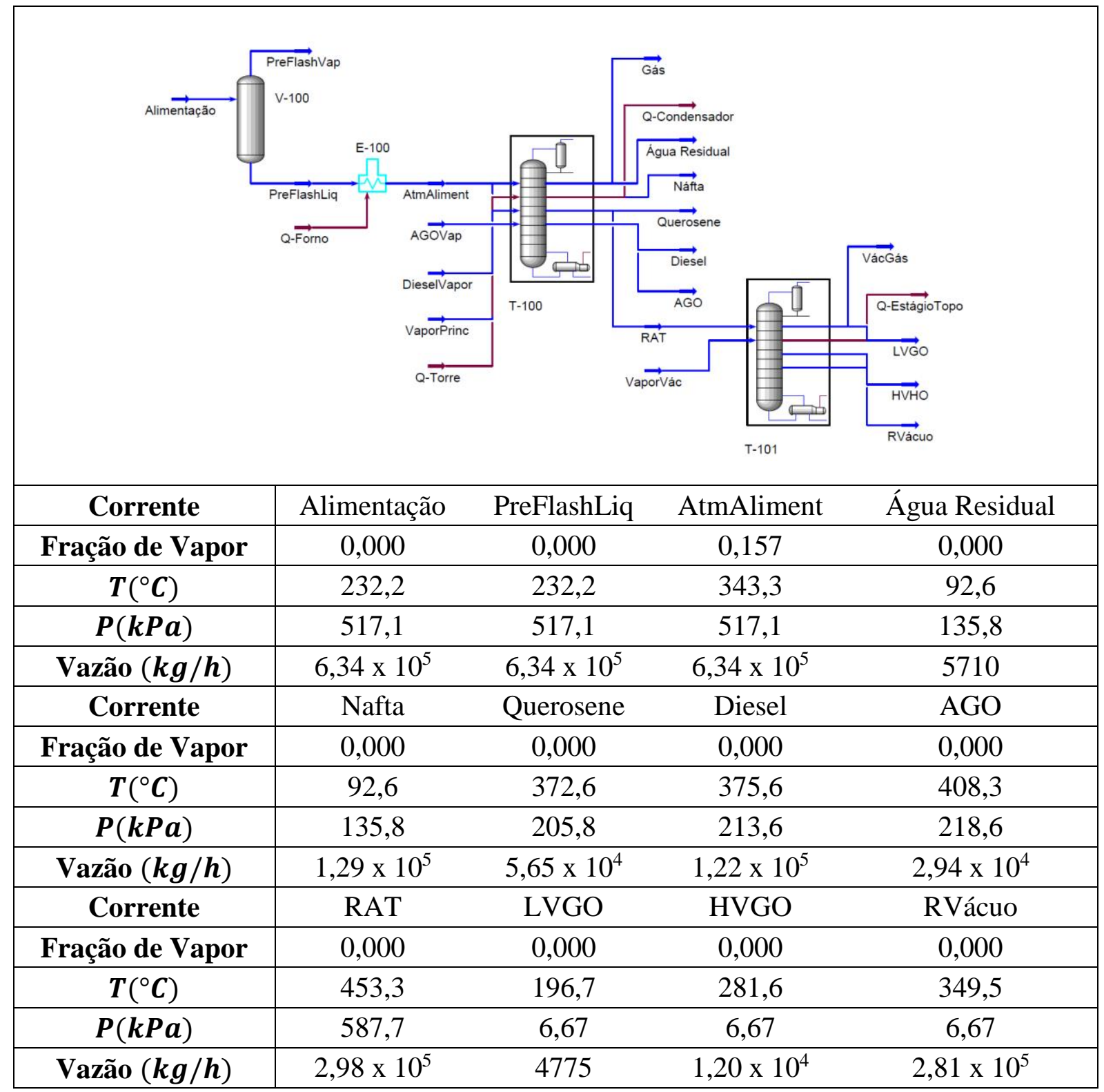

Figura 2 - PFD padrão para a unidade. 
Os dados experimentais de ${ }^{\circ} \mathrm{API}$ e de PEV foram inseridos no software, sendo que a equação de Peng-Robinson foi usada para representar o comportamento das fases líquida e vapor. Foi definido um número de 28 pseudocomponentes para representar cada petróleo como um mistura desses, de acordo com o critério demonstrado em Fahim et al. (2009). As condições operacionais para a implementação das colunas, bem como todas as especificações utilizadas estão descritas nas Tabelas 2 a 4.

Tabela 2 - Condições operacionais para a coluna atmosférica

\begin{tabular}{|c|c|}
\hline Condições da carga & $\begin{array}{l}T=25^{\circ} \mathrm{C} ; P=101,3 \mathrm{kPa} \\
\dot{v}=662,5 \mathrm{~m}^{3} / \mathrm{h} \text { (vazão da carga) }\end{array}$ \\
\hline Aquecedor da carga & $\begin{array}{l}T=330^{\circ} \mathrm{C} \text { (temperatura de saída) } \\
\Delta P=34,47 \mathrm{kPa}\end{array}$ \\
\hline Condições da coluna & $\begin{array}{l}N_{t}=29 \text { (número de estágios teóricos) } \\
F_{p}=28 \text { (estágio de alimentação) } \\
\Delta P_{c}=62,05 \mathrm{kPa} \text { (no condensador) } \\
P_{c}=135,8 \mathrm{kPa} \text { (pressão no condensador) } \\
P_{f}=218,6 \mathrm{kPa} \text { (pressão no fundo) } \\
T_{c}=37,8^{\circ} \mathrm{C} \text { (no condensador) } \\
T_{p t s}=121,1^{\circ} \mathrm{C} \text { (no estágio de topo) } \\
T_{b t s}=315,6^{\circ} \mathrm{C} \text { (no fundo) }\end{array}$ \\
\hline Vapor para stripping da coluna & $\begin{array}{l}T=190,6^{\circ} \mathrm{C} ; P=1034,2 \mathrm{kPa} \\
\dot{M}_{m s}=3402 \mathrm{~kg} / \mathrm{h} \text { (vazão mássica) }\end{array}$ \\
\hline Vapor para o stripper lateral de diesel & $\begin{array}{l}T=148,9^{\circ} \mathrm{C} ; P=344,7 \mathrm{kPa} \\
\dot{M}_{d s}=1360,8 \mathrm{~kg} / \mathrm{h}\end{array}$ \\
\hline Vapor para o stripper lateral de AGO & $\begin{array}{l}T=148,9^{\circ} \mathrm{C} ; \mathrm{P}=344,7 \mathrm{kPa} \\
\dot{M}_{A s}=1134 \mathrm{~kg} / \mathrm{h}\end{array}$ \\
\hline Especificações Gerais & $\begin{array}{l}\text { Vazão de Nafta }=152,4 \mathrm{~m}^{3} / \text { dia } \\
7,91 \times 10^{6} \mathrm{~kJ} / \mathrm{h} \text { (no Stripper de querosene) }\end{array}$ \\
\hline
\end{tabular}

Tabela 2 - Especificação strippers laterais da coluna atmosférica

\begin{tabular}{|c|ccc|}
\hline Stripper & Estágio de Retirada & Estágio de Retorno & $\dot{\boldsymbol{v}}\left(\boldsymbol{m}^{\mathbf{3}} \boldsymbol{/ h}\right)$ \\
\hline Kero - SS & 9 & 8 & 61,61 \\
\hline Diesel - SS & 17 & 16 & 127,5 \\
\hline AGO - SS & 22 & 21 & 29,81 \\
\hline
\end{tabular}


Tabela 3 - Especificação para refluxos circulantes da coluna atmosférica

\begin{tabular}{|c|cccc|}
\hline $\begin{array}{c}\text { Refluxo } \\
\text { circulante }\end{array}$ & Estágio Retirada & Estágio Retorno & $\dot{\boldsymbol{v}}\left(\boldsymbol{m}^{\mathbf{3}} / \boldsymbol{h}\right)$ & $\begin{array}{c}\text { Carga Térmica } \\
(\boldsymbol{k W})\end{array}$ \\
\hline PA 1 & 2 & 1 & $-1,61 \times 10^{7}$ \\
\hline PA 2 & 17 & 16 & $-1,03 \times 10^{7}$ \\
\hline PA 3 & 22 & 21 & $-1,03 \times 10^{7}$ \\
\hline
\end{tabular}

Tabela 4 - Condições operacionais e especificações para a coluna vácuo

\begin{tabular}{|l|l|}
\hline \multirow{4}{*}{ Condições } & $N_{t}=9$ (número de estágios teóricos) \\
& $F_{p}=8$ (estágio de alimentação) \\
& $P_{t}=11 \mathrm{kPa}$ (pressão no topo) \\
& $P_{f}=13 \mathrm{kPa}$ (pressão no fundo) \\
& $T_{t}=120^{\circ} \mathrm{C}$ (no topo) \\
& $T_{f}=370^{\circ} \mathrm{C}$ (no fundo) \\
\hline \multirow{5}{*}{ Especificações Gerais } & Vazão de topo $=2600 \mathrm{~kg} / \mathrm{h}$ \\
& Vazão de LVGO $=33 \mathrm{~m}^{3} / \mathrm{h}$ \\
& Vazão de $\mathrm{HVGO}=90 \mathrm{~m}^{3} / \mathrm{h}$ \\
\hline
\end{tabular}

Após a inserção de todos estes dados no software, os balanços de massa e energia foram resolvidos com as ferramentas numéricas no mesmo.

\section{RESULTADOS E DISCUSSÕES}

A Figura 3 mostra os resultados da avaliação energética para os casos em que o processo de destilação é simulado como duas colunas em série, ou somente com uma coluna a vácuo, onde o petróleo cru é diretamente carregado na unidade. Pela análise da Figura 3, ocorreu um intervalor de inversão das cargas térmicas a partir de um valor de ${ }^{\circ} \mathrm{API}$ aproximadamente igual 25,5. Até o início deste intervalo, a partir do valor 8,10 para o ${ }^{\circ} \mathrm{API}$ correspondente ao petróleo ZUATA, as cargas térmicas para o processo com duas colunas em série são maiores do que aquelas para uma única coluna a vácuo. Portanto, para petróleos pesados, é recomendável que o processo de destilação seja efetuado com uma coluna a vácuo.

As Figuras 4 e 5 mostram os perfis de temperatura para os petróleos MEREY e GRSOL09X em uma coluna atmosférica. No caso do primeiro perfil, as temperaturas dos estágios de fundo resultaram em valores que ultrapassam o valor de $450^{\circ} \mathrm{C}$ para a ocorrência de reações de craqueamento. Logo, deve-se evitar a destilação atmosférica com esse petróleo, sendo recomendado o projeto de uma única coluna a vácuo. No segundo perfil, as temperaturas de fundo não ultrapassaram o limite de $450^{\circ} \mathrm{C}$, sendo possível a realização da destilação atmosférica sem maiores problemas. 


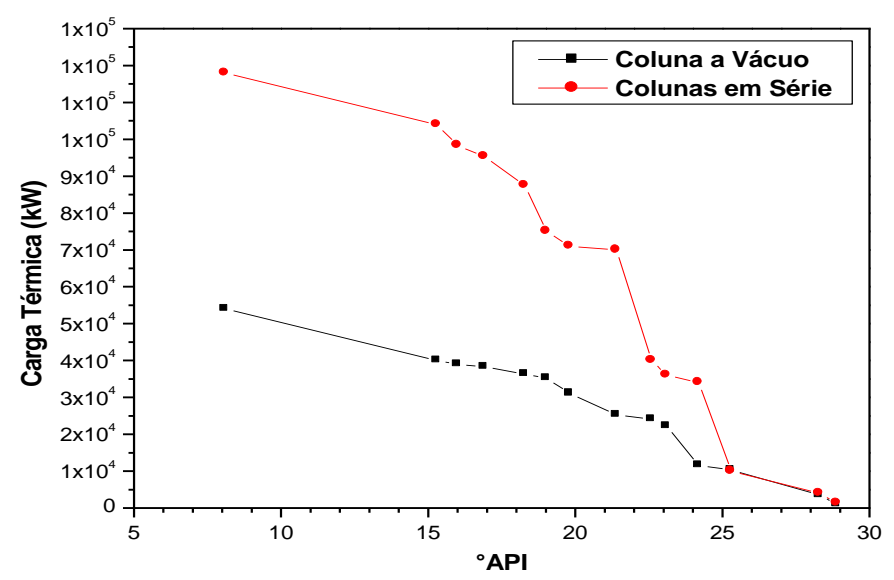

Figura 3 - Cargas térmicas das colunas em série e da coluna a vácuo.

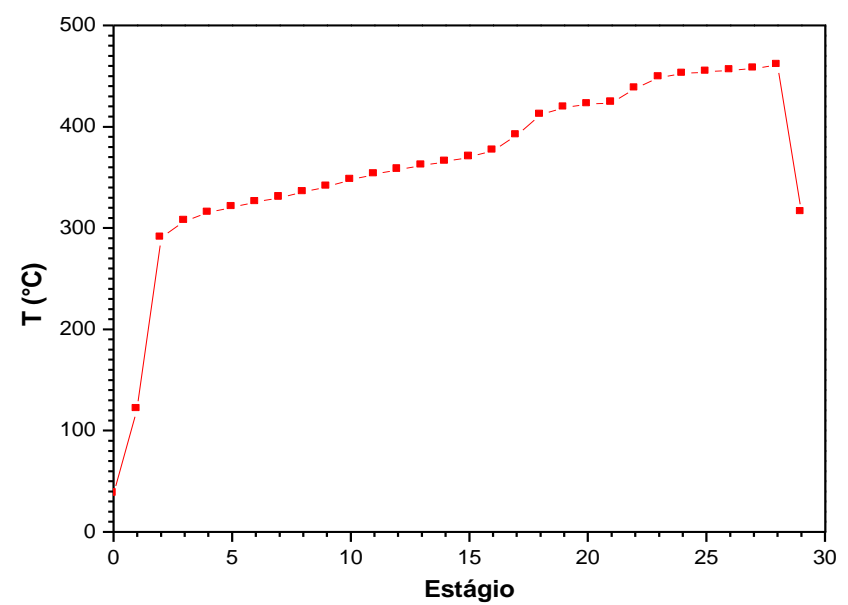

Figura 4 - Perfil de temperatura para o petróleo MEREY.

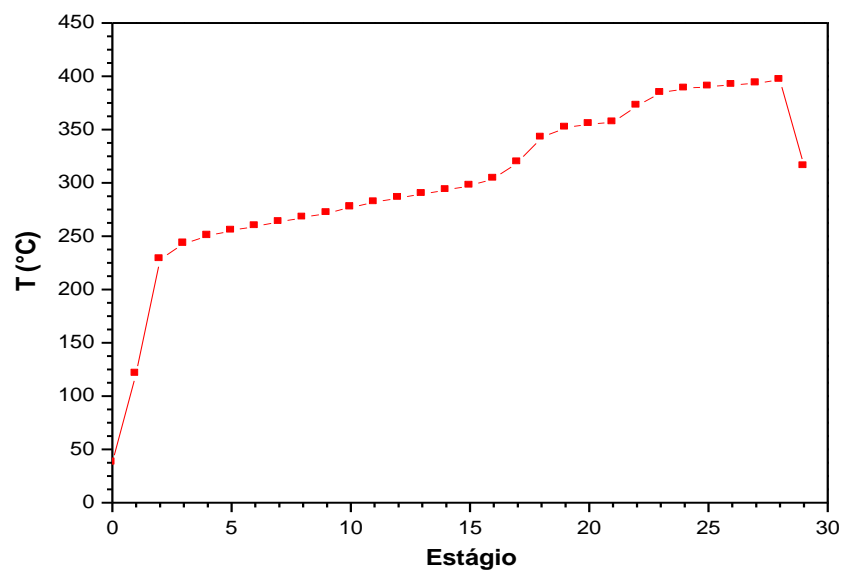

Figura 5 - Perfil de temperatura para o petróleo GRSOL09X. 


\section{CONCLUSÕES}

Baseado nos resultados apresentados neste trabalho, foi possível concluir o seguinte:

- A simulação demonstrou que as cargas térmicas para o processo com duas colunas série são maiores que aquelas para o processo com uma única coluna vácuo. Para valores crescentes do ${ }^{\circ}$ API até aproximadamente 25,5, é aconselhável do ponto de vista energético o uso de uma única coluna a vácuo. Para valores mais elevados, pode-se se utilizar o sistema em série;

- Adicionalmente, as temperaturas dos estágios de fundo para petróleos pesados, ou com baixos valores de ${ }^{\circ} \mathrm{API}$, são maiores que um valor limite, acima do qual se iniciam as reações de craqueamento térmico.

\section{REFERÊNCIAS}

ASPEN HYSYS. Operation Guide. Burlington, MA, USA: Aspen Technology, 2011.

BELLET, A. Molecular Distillation: An Analytical Tool for Heavy and Extra-Heavy Crude Oil Assays. Los Teques, Venezuela: PDVSA, 1998.

BOMBARDELLI, C. et al. O Processo de Incrustação por Coque na Indústria do Petróleo. In: Congresso Brasileiro de P \& D em Petróleo e Gás, 3., 2004, Salvador. Anais... Salvador: IBP, 2004. P. 3.

CHEVRON. Chevron Crude Oil Marketing. Disponível em http://crudemarketing.chevron.com/. Acesso em: 23 de março de 2014.

EXXONMOBIL. ExxonMobil Refining \& Suplly. Disponível em: http://www.exxonmobil.com/crudeoil/. Acesso em: 23 de março de 2014.

FAHIM, M. A.; AL-SAHHAF T. A.; ELKILANI A. S. Fundamentals of Petroleum Refining. Oxford, UK: Elsevier, 2009.

GARY, J. H.; HANDWERK G. E. Petroleum Refining: Technology and Economics. New York, USA: Marcel Dekker, 2001.

SZLKO, A.; ULLER, V. C. Fundamentos do Refino de Petróleo: Tecnologia e Economia. Rio de Janeiro: Interciência, 2008.

TOTAL S. A. TOTSA TOTAL Oil Trading S. A. Disponível em http://www.totsa.com/pub/crude/crude_assays.php?rub=1. Acesso em: 23 de março de 2014.

TOWLER, G.; SINNOT, R. Chemical Engineering Design: Principles, Practice and Economics of Plant and Process Design. Oxford, UK: Elsevier, 2008.

YAMANISHI, E. Simulação, Análise e Otimização das Colunas Atmosférica e Debutanizadora da Unidade de Destilação de Refino de Petróleo. Campinas, SP: Unicamp, 2007. Originalmente apresentada como dissertação de mestrado. 